Chlorophorin, therefore, appears to be a stilbene derivative (ef. pinosylvin ${ }^{1}$ ), to which the following partial structure can be assigned.

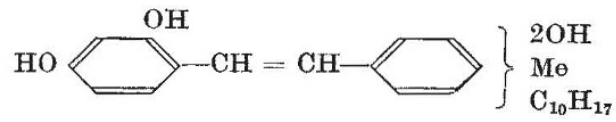

The aliphatic side-chain, $\mathrm{C}_{10} \mathrm{H}_{17}$, contains two double bonds, one of which is reduced (in addition to that present in the stilbene residue) on catalytic hydrogenation, giving the substituent $-\mathrm{CH}_{2} \mathrm{CH}$ : $\mathrm{C}(\mathrm{Me})\left(\mathrm{CH}_{2}\right)_{3} \mathrm{CHMe}_{2}$.

Dyson Perrins Laboratory, M. F. GRUNDON F. E. KING

University, Oxford.

University, Nottingham. Feb. 16.

${ }^{1}$ Erdtman, Ann., 539, 116 (1939).

\section{Formation of Trivalent Cobalt Complexes in Protein Hydrolysates}

E. Lester Smith ${ }^{1}$, and later E. L. Rickes et al. ${ }^{2}$, have reported that the pure anti-pernicious anæmia principle (vitamin $\mathrm{B}_{12}$ ) isolated by them ${ }^{3,4}$ was a cobalt complex, containing as much as 4 per cent cobalt dry weight. Immediately after we had been informed about this extraordinary fact by Dr. Lester Smith of Glaxo Laboratories ${ }^{5}$, we started the present investigation. We were able first to show that all the amino-acids available to us (see table), with the exception of tryptophane, when treated with cobalt (II) chloride and hydrogen peroxide under suitable conditions, gave solutions the colour of which showed much resemblance to that of a sample of Lester Smith's preparation.

$\quad$ Amino-acid
Glycine
$d l$-Alanine
$d l$-Valine
$l$-Cystine
$d l$-Threonine
$l$-Glutamic acid
$d l$-norLeucine
$d l$-isoLeucine
$d l$-Leucine
$d l$-Lysine
$l$-Arginine
$d l$-Asparagine
$d l$-Aspartic acid
$d l$-Phenylalanine
$d l$-Tyrosine
$l$-Tryptophane
$l$-Proline
$l$-Histidine

Colour developed with Co (II) chlor
Purple
Purple
Purple
Purple
Purple
Purple (weak)
Purple
Purple
Purple
Purple
Purple
Purple
Purple
Purple (faint)
Purple (very faint)
Yellow
Purple
Purple

Afterwards we were able to show that, on treating slightly acid protein hydrolysates with cobalt chloride and hydrogen peroxide, solutions of a dark mahogany colour were obtained. This coloured material could not be dialysed through 'Cellophane' membranes. By applying the procedure of Laland and Klem ${ }^{6}$ for the purification of the anti-pernicious anæmia factor, we were able to show that the colour passed into the phenol, and from the phenol back into the aqueous phase when four volumes of ether were added. From the slightly acid solution the coloured complex was adsorbed to charcoal, and could not be eluated either by 6 per cent phenol-water or by 96 per cent ethanol. All the coloured material could be removed by glacial acetic acid, and from this it could be precipitated as a pinkish powder by ethyl ether. This powder is easily soluble in water, yielding a purplish-brown solution.

Later, we were able to show that when a protein, for example, casein, is treated with papain and cobalt chloride at neutral reaction, most of the cobalt is bound by the casein, which does not seem to be attacked by the papain under the conditions stated. If one then digests the cobalt-casein complex by means of trypsin, the complex goes into solution, while most of the casein remains undigested. This coloured complex, too, is easily soluble in phenol. The sequence of these procedures may also be reversed, the casein being first digested with trypsin, and then the hydrolysate treated with papain and cobalt chloride for $24-48$ hours at $37^{\circ} \mathrm{C}$. In this case also a similar complex is obtained.

When using meat as a starting material, much of the colour is not adsorbed by charcoal, and some of it may also be removed by treating charcoal adsorbate with 6 per cent phenol-water. The material which goes into the filtrate is precipitated by ethanol, and may be transformed into a powder with a pinkish hue by washing repeatedly with 96 per cent ethanol and finally with ether.

A few of our fractions have been subjected to clinical trial with respect to anti-pernicious anæmia potency. So far, only a weak reticulocyte response (up to 4 per cent) but no marked effect upon the red count or the hrmoglobin have been observed. Further trials are in progress.

Research Laboratories,

Per Laland KaRL Closs

Nyegaard and Co., A/S, Oslo.

Sept. 28.

${ }^{1}$ Smith, E. Lester, Nature, 162, 144 (1948).

${ }^{2}$ Rickes, E. L., Brink, N. G., Koniuszy, F. R., Wood, T. R., and Folkers, K., Science, 108, 134 (1948).

${ }^{3}$ Rickes, E. L., et al., Science, 107, 396 (1948).

${ }^{4}$ Smith, E. Lester, Nature, 161, 638 (1948).

s Private communication.

${ }^{6}$ Laland. P., and Klem, Aa, Acta Med. Scand., 88, 620 (1936).

\section{A Quinonoid Structure for Hydroquinone Pyridinium Salts of Organic Acids}

HYDROQuINONE pyridinium salts of organic acids, for example, formate and acetate, were prepared by the action of pyridine on $p$-quinone in presence of formic or acetic acid ${ }^{1}$. These salts are found by analysis not to contain active hydrogen. They are not methylated by diazomethane or dimethylsulphate, nor acetylated by acetic anhydride; and in all these experiments the materials were recovered almost unchanged. So far as could be ascertained from the literature, the preparation of such derivatives has not hitherto been attempted.
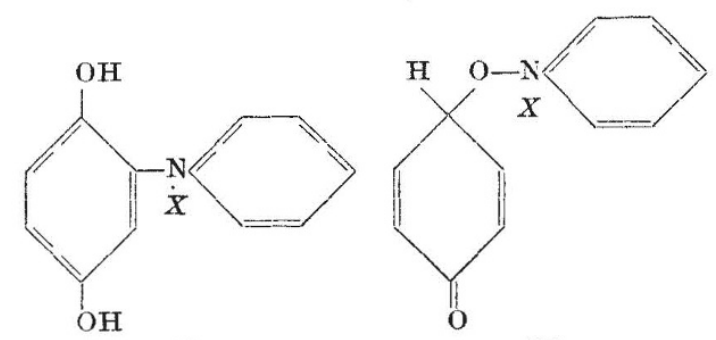

(I) (II) 